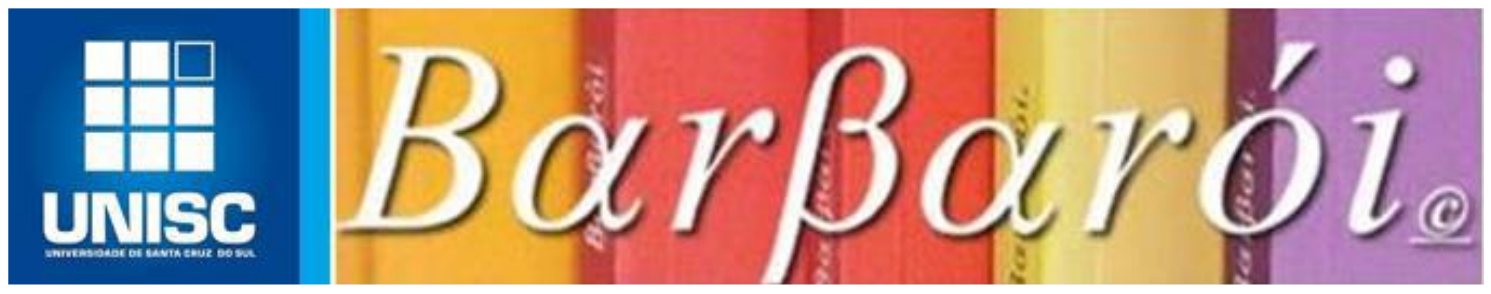

\title{
POBREZA, PROTEÇÃO SOCIAL E CIDADANIA: UMA ANÁLISE DO DIREITO À SAÚDE NO BRA̧SIL A PARTIR DA CONSTITUIÇÃO FEDERAL DE 1988
}

DOI: http://dx.doi.org/10.17058/barbaroi.v0i0.8182

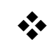 \\ Edith Maria Barbosa Ramos \\ Universidade Federal do Maranhão - UFMA - Brasil \\ Isadora Moraes Diniz \\ Universidade Federal do Maranhão - UFMA - Brasil

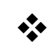

\section{Resumo}

O presente artigo teve por escopo analisar o processo de constituição da ideia do direito à saúde enquanto direito social no Brasil, integrante do rol de direitos fundamentais insculpidos na Constituição Federal de 1988. Para tanto realizou-se uma concisairrupção histórica no processo de construção da concepção de proteção social na Europa ocidental. Objetivou-se, ainda, analisar a proteção social enquanto elemento essencial da cidadania. Buscou-se compreender a seguridade social como núcleo do Estado de Bem-Estar e discutir o contexto de inserção da questão do direito à saúde na agenda pública. A presente pesquisa utilizou-se dométodo de pesquisa dedutivo, com a apropriação dos conceitos de proteção social e direitos sociais, refletindo sobre as determinações dos conteúdos presentes na concepção constitucional do direito à saúde.

Palavras-chave: Proteção Social. Direito à Saúde. Constituição Federal.

\section{Introdução}

O presente artigo teve por escopo analisaro processo de constituição da ideia de direito à saúde como direito social no Brasil, integrante do rol de direitos fundamentais insculpidos na Constituição Federal de 1988. Para tanto realizou uma concisa irrupção histórica no processo de construção da ideia de proteção social nos países da Europa ocidental, notadamente Alemanha e Inglaterra.

Objetivou-se analisar a proteção social enquanto elemento essencial do conceito de cidadania, a partir das reflexões desenvolvidas por Marshall (1967). Destacou-se que no século XIX a pobreza era vista como desvio de caráter, uma propensão individual à vagabundagem e mendicância. Perspectiva que acabou por vincular intrinsecamente a 
possibilidade de assistência social à prestação de um trabalho formal correspondente. Empreendeu-se uma reflexão sobre as causas efetivas da pobreza e como essas causas deixaram de ser consideradas em sua plenitude, na medida em que foram subestimados os efeitos sociais das transformações econômicas e políticas.

Buscou-se, ainda, demonstrar que a pobreza como produto do desenvolvimento predatório do capitalismo e que as mobilizações das classes trabalhadoras modificaram significativamente a arena política, a moldura jurídica e o conceito de cidadania no século XX. Colocou-se em evidência a necessidade de reinvenção do capitalismo, no período seguinte à Segunda Grande Guerra, e como foi forjado o modelo de Estado de Bem-Estar Social na Europa ocidental.

Ressaltou-se a ideia de mínimos sociais e a inserção dos direitos sociais como elemento integrante do status da cidadania. Abordou-se a seguridade social como núcleo do Estado de Bem-Estar e discutiu-se o contexto de inserção da questão do direito à saúde na agenda pública. Evidenciou-se os principais documentos internacionais para demonstrar que o direito à saúde está relacionado com a qualidade de vida das pessoas e que a Constituição brasileira de 1988 representa importante instrumento na proteção do direito à saúde no país. O direito à saúde, no Brasil, está declarado no artigo $6^{\circ}$, capítulo II, Título II da CF/88 (Dos Direitos Fundamentais), assim como está inserto no Capítulo II, do Título VIII da CF/88 (Da Ordem Social), que trata especificadamente da Seguridade Social. Por fim, destacou-se que o direito à saúde ultrapassa questões meramente biológicas, e que inclui questões eminentementesociais em seu cerne. Ressaltou-se a criação do Sistema Único de Saúde, com a Lei $\mathrm{n}^{\circ}$ 8.080/90, e, finalmente,analisou-se a atualidade do direito à saúde e a premente necessidade de sua proteção enquanto conquista histórica.

Em razão disso, na presente investigação, foram analisados documentos oficiais e textos normativos expedidos por organismos nacionais e internacionais que tratam da temática da proteção social e do direito à saúde. O conjunto de documentos e textos normativos coletados contemplou tratados, constituições, declarações, legislações e normas infralegais. Foram, assim, considerados válidos os documentos e textos normativos que permitiram o levantamento de informações no campo das dimensões indicadas na configuração do objeto pesquisado.

Procedeu-se uma análise histórica e conceitual da ideia de proteção social na Europa ocidental e da construção da concepção de direito à saúde no Brasil, objetivando compreender os determinantes que propiciaram sua constituição, bem como a atualização do seu processo de proteção. Portanto, este texto concentra-se em uma oportunidade, do ponto de vista Barbarói, Santa Cruz do Sul, n.55, p.<57-80>,jul./dez. 2019 
científico, para aquele que pretende discutir o direito à saúde no interior do sistema de proteção sociale em que medida a construção normativa possui envergadura para enfrentar as desigualdades sociais.

Tal oportunidade justificou o esforço científico aqui materializado no percurso metodológico necessário para pôr em questão o seguinte pressuposto: sem a efetiva concretização de uma proteção social justiça e sem a superação do elevado grau de desigualdades na consecução do direito à saúde, a confecção da Constituição Federal brasileira de 1988, como a confecção de qualquer norma pode representar apenas retórica. Procurou-se, assim, verificar a articulação entre o proteção social e direito à saúde, a partir de uma concepção saúde como direito fundamental social.

Em razão disso, a presente pesquisa utilizou o método de dedutivo, com a apropriação histórica de conceitos como proteção social, direito à saúde e cidadania. Para o levantamento de informações, os principais procedimentos de coleta de dados foram bibliográficos e documentais (MARCONI; LAKATOS, 2007). Foram selecionados livros, artigos e documentos normativos, tendo como descritor de buscas, os termos: Proteção Social; Direito à Saúde e Cidadania. Revisaram-se artigos publicados em revistas científicas, estratificadas no sistema Qualis,bem como artigos constante na base de dados Bireme, por meio dos serviços da Medline, Scielo e Lilacs. Destaque-se que se procurou superar posturas metodológicas rígidas, demarcando a análise em diversas variáveis contextuais, quais sejam, jurídica, social, econômica e política, a fim de que se evitasse considerações maniqueístas e sem objetivação científica e se conseguisse empreender uma investigação socialmente situada.

\section{$1 \mathrm{O}$ direito à saúde dentro do contexto histórico da proteção social na Alemanha e Inglaterra}

Não há como discutir direito à saúde sem antes fazer uma irrupção histórica, ainda que concisa, na temática da proteção social enquanto fator basilar da cidadania. Marshall (1967, p. 63) dividiu o conceito de cidadania em três partes ou elementos, quais sejam: o civil, o político e o social. A análise marshalliana é ditada mais pela história que pela lógica e está situada na sociedade inglesa, onde esses elementos da cidadania foram se desenvolvendo e se incorporando ao conceito durante três séculos.

O elemento civil da cidadania é composto dos direitos necessários à liberdade individual, formou-se no decorrer do século XVIII, sobretudo, em razão do trabalho dos tribunais de justiça ( instituições mais intimamente associadas com os direitos civis), que, pouco a pouco foram adicionando ao status do homem livre uma série de direitos essenciais Barbarói, Santa Cruz do Sul, n.55, p.<57-80>,jul./dez. 2019 
ao exercício da liberdade individual, quais sejam: a liberdade de ir e vir; a liberdade de imprensa, pensamento e fé; o direito à propriedade e o de concluir contratos válidos e o direito à justiça. Para o Marshall este último difere dos outros - porque o direito à justiça é o direito de defender e afirmar todos os direitos em termos de igualdade com os outros e pelo devido encaminhamento processual (1967, p. 63).

Já os direitos políticos começaram a ser formados no início século XIX, "quando os direitos civis ligados ao status de liberdade já haviam conquistado substância suficiente para justificar que se fale de um status geral de cidadania" (MARSHALL, 1967, p. 69). A formação desses direitos não se caracteriza pelo surgimento de novos direitos, mas sim pela distribuição de velhos direitos a vários setores da população marginalizados politicamente. Dessa forma, paulatinamente ampliaram-se aos indivíduos o direito à participação no exercício do poder político, como um membro de um organismo investido da autoridade política ou como um eleitor dos membros de tal organismo " (MARSHALL, 1967, p. 63).As instituições correspondentes aos direitos políticos são o Parlamento e Conselhos de Governo Local.

Os direitos sociais, por sua vez, passaram a compor o status da cidadania somente no século XX. Esses direitos se referem desde o direito a um mínimo de bem-estar econômico e segurança ao direito de participar, por completo na herança social e levar a vida de um ser civilizado de acordo com padrões que prevalecem na sociedade (MARSHALL, 1967, p. 6364). No entanto, as bases incipientes dos serviços públicos como prestação do Estado começaram a ser lançadas ainda no século XIX com a Lei Revisora das Leis dos Pobres (Poor Law Amendment Act) de 1834, que previa a concessão de prestações sociais pelo Estado não enquanto direitos, mas segundo o paradigma da caridade a fim de aliviar os efeitos indesejados da miséria extrema. As instituições mais ligadas a esses direitos são o sistema educacional e os serviços sociais (MARSHALL, 1967, p. 64).

Deve-se ressaltar, como fez Pereira (2009, p. 238) que o fenômeno da pobreza é mundial e surgiu com as primeiras sociedades. Entretanto, no período pré-capitalista a pobreza deu-se num contexto de escassez e de precário desenvolvimento das forças produtivas. Além disso, afirma a autora, que a exploração do homem pelo homem não escondia ideologias, pois era realizada de maneira direta, óbvia e legitimada: os senhores de escravos e os senhores feudais, respectivamente, tinham direitos sobre seus escravos e servos, podendo exigir trabalho e servidão em troca de condições de sobrevivência. Com a crescente ameaça da pobreza ao sistema estabelecido surge em 1601 a primeira Poor Laws (PEREIRA, 2009, p. 238), masos indivíduos para se valerem dessa assistência social precisavam se despir Barbarói, Santa Cruz do Sul, n.55, p.<57-80>,jul./dez. 2019 
de qualquer direito de cidadania, renunciando a sua liberdade, rompendo seus laços familiares e se submetendo a jornadas de trabalho excessivas.

Em outras palavras, como alerta Pereira $(2009$, 239) com a industrialização e o advento do mercado de trabalho, a pobreza não mais se configurou pela escassez. As forças produtivas estavam mais desenvolvidas e produziam uma proporção cada vez maior de bens e riquezas. Ao mesmo tempo, e paradoxalmente, a pobreza aumentava na mesma magnitude que as condições de superação da escassez. Na verdade, a pobreza que se formava era um fenômeno novo, desconhecido. Além disso, para a autora,no momento em que uma determinada classe social se apoderou das riquezas e dos meios de produção, e outra não possuía nada mais além de sua força de trabalho, a pobreza até então conhecida por alguns, tornou-se de massa. E mais, os pobres que se multiplicavam não eram considerados vítimas e merecedores de proteção devida, mas, ao contrário, culpados pela sua condição (PEREIRA, 2009, p.240). A pobreza era vista quase como um crime, um desvio de caráter que fazia com que o indivíduo, não acometido por qualquer incapacidade, ficasse propenso à vagabundagem e à mendicância. Assim, era dos pobres, portanto, a culpa pela pobreza. Por isso, não poderia haver qualquer assistência sem a prestação de um trabalho correspondente (PEREIRA, 2008).

Dessa forma, durante a vigência da Lei dos Pobres, as verdadeiras causas da pobreza não foram consideradas, na medida em que eram subestimados os efeitos sociais da rápida transformação da economia agrária para a industrial, da transferência de forma abrupta da vida social do campo para a cidade, do desemprego decorrente dos avanços tecnológicos, das flutuações dos salários, das precárias, perigosas, insalubres e extenuantes exigências de trabalho e da ausência de educação e lazer. Todos esses elementos expuseram "inevitavelmente a fragilidade da doutrina utilitarista que atribuía ao pobre e às antigas Poor Laws a culpa pelo pauperismo" (PEREIRA, 2008, p. 79). Giovanni (1998, p. 31) destaca, ainda, que:

\footnotetext{
Inicialmente na Inglaterra e depois nos outros países europeus, os processos de industrialização e urbanização, trouxeram o agravamento dos problemas ligados à pobreza (até então relativamente controlados). As péssimas condições de trabalho vigentes entre a massa proletária que se constituía, o infortúnio, os acidentes, as doenças profissionais e o desemprego tornavam-se cada vez mais evidentes. A conjugação de todos estes fatores - aliada à crescente organização das classes trabalhadoras através de sindicatos, a constituição de partidos políticos de inspiração socialista comunista ou laborista, no bojo da expansão dos direitos políticos evidenciaria, no plano das visões de mundo de então, que a pobreza não era uma decorrência dos méritos (ou deméritos) e performances pessoais, mas um fenômeno ligado a uma relação muito estreita com as condições sociais de vida e, particularmente, de trabalho. Ou pelo menos, que se estava diante de outro tipo de pobreza: não aquela dos parias, dos loucos e doentes, mas a pobreza paradoxal daqueles que trabalhavam.
} 
Ao analisar o fenômeno da pobreza, faz-se necessário levar em consideração as diferenças econômicas, históricas e culturais entre os povos (PEREIRA, 2009, p. 231). Com efeito, a Revolução Industrial elevou ao máximo a exploração do homem, que era submetido a uma longa jornada de trabalho em troca de um mísero salário, situação que agravou o quadro de pobreza e, por conseguinte, os problemas sociais que a ela se associavam.

Desta forma, foi a partir do Welfare State, cuja origem remonta ao final do século XIX, e que, apesar de manter a classe trabalhadora na mesma situação desigual, ofereceu proteção social e segurança no trabalho (PEREIRA, 2009, p. 241). Contudo, como observa Pereira (2009, p. 241) essa organização social e política, que se consolidou no século XX, e era baseada na doutrina econômica keynesiana e no regime de produção fordista, somente funcionou plenamente até meados dos anos 1970. As vicissitudes do sistema capitalista permitiram que percebesse que a pobreza não era fruto da vagabundagem, mas sim produto do próprio desenvolvimento predatório do capitalismo, que explorava ao máximo o trabalho em nome do capital, resultando na contraditória existência da opulência e da riqueza ao lado da miséria absoluta.

Nesse contexto, e como consequência da expansão dos direitos civis e políticos, aumentaram as mobilizações sociais, especialmente dos trabalhadores que lutavam em prol da melhoria das condições de vida e de trabalho, circunstância que, conforme Pereira (2008), resultou nas batalhas pelo alargamento do conceito de cidadania das esferas civil e política para a social, de modo que os trabalhadores passaram a requerer as prestações sociais como direitos devidos pelo Estado.Polanyi (1980, p. 163-164) observou que a história social e política do século XIX foi marcada por um duplo movimento, que pode ser personificado como:

[...] a ação de dois princípios organizadores da sociedade, cada um deles determinando seus objetivos institucionais específicos, com o apoio de forças sociais definidas e utilizando diferentes métodos próprios. Um foi o princípio do liberalismo econômico, que objetivava estabelecer um mercado auto-regulável, dependia do apoio das classes comerciais e usava principalmente o laissez-faire e o livre comércio como seus métodos. O outro foi o princípio da proteção social, cuja finalidade era preservar o homem e a natureza, além da organização produtiva, e que dependia do apoio daqueles mais imediatamente afetados pela ação deletéria do mercado - básica, mas não exclusivamente, as classes trabalhadores e fundiárias - e que utilizava uma legislação protetora, associações restritivas e outros instrumentos de intervenção com seus métodos.

Destarte, se de um lado o paradigma do mercado autorregulável se expandia, do outro cresciam as críticas e as pressões contra o pauperismo das massas, que cada vez mais "ganhavam adeptos e forneciam elementos que justificavam, já no século XIX, a introdução de medidas pontuais de proteção social, ao arrepio dos princípios liberais" (PEREIRA, 2008, 
p. 81). E em resposta às pressões dos trabalhadores, que tinham suas condições de vida deterioradas, foram lançadas no final do século XIX, no governo alemão do Chanceler Otto Von Bismarck, as bases da seguridade social, que inclui, dentre outros, os serviços de saúde. O esquema bismarkiano existiu na Alemanha entre 1883 e 1889 e constituiu-se em um esquema de seguridade social instituído pelo governo conservador do Chanceler, cuja a principal função, para Pereira (2000, p. 18), era desmobilizar a classe trabalhadora, que se sentia atraída pelas ideias socialistas da social democracia alemã. Esse esquema contemplava seguro saúde, seguro acidentes de trabalho e a aposentadoria. Vinculava-se exclusivamente ao trabalho e, por isso, só atendia pessoas empregadas, mediante contrato e prévia contribuição.

No modelo bismarckiano, somente os trabalhadores e suas famílias podiam usufruir dos benefícios da seguridade social, uma vez que o acesso condicionado a uma contribuição direta anterior (descontada nas folhas de pagamento dos salários) e o montante das prestações era proporcional à contribuição efetuada. $\mathrm{O}$ modelo era, portanto, uma espécie de seguro social, que, apesar de representar um avanço na prestação de serviços sociais pelo Estadoquando comparado com a Lei dos Pobres de 1834, deixava parte da população fora da cobertura da seguridade social (LIMA, 1957).

O ápice do princípio da proteção social somente foi alcançado após a Segunda Guerra Mundial, quando o capitalismo, diante do quadro de instabilidade política, social e econômica mundial, precisou se reinventar. Em prol da manutenção do modo capitalista, acolheu-se demandas por maior igualdade e reconhecimento dos direitos sociais e segurança econômica, forjando-se um novo modelo de organização estatal - o Estado de Bem-Estar Social, que, ancorando-se nos conceitos de seguridade e cidadania social, assumiu o papel de prover serviços sociais, enquanto direito assegurado pelo Estado e de dimensões quase universais.

Um dos pilares do Welfare State foi o Plano Beveridge, que, formulado durante a Segunda Guerra Mundial na Inglaterra, propôs uma revisão completa do sistema de proteção social inglês, mudando o objetivo dessas políticas, vale dizer, substituindo o escopo de proteção dos trabalhadores contra as situações de risco por um objetivo maior: o combate à pobreza. Segundo Pereira (2000, p. 18) o Plano Beveridge realizou um exame dos projetos existentes de seguro social e serviços afins, a partir daí fez um diagnóstico da miséria, com o escopo de definir e/ou aperfeiçoar projetos de seguridade social em três aspectos principais; quais sejam: ampliação do alcance, ampliação dos objetivos de cobertura de riscos e aumento das taxas de benefícios.

No sistema beveridgiano, os direitos sociais passaram a ter caráter universal, destinados incondicionalmente a todos os cidadãos, a fim de garantir a todos que se Barbarói, Santa Cruz do Sul, n.55, p.<57-8o>,jul./dez. 2019 
encontravam em condições de necessidade os mínimos sociais. Conforme Pereira (2000, p. $122-123)$,

\begin{abstract}
A partir daí, os mínimos sociais passaram a ter uma conotação mais alargada, incluindo, além de políticas de manutenção de renda - geralmente sob a forma de uma rede de segurança impeditiva do resvalo de cidadãos social e economicamente vulneráveis para baixo de uma linha de pobreza legitimada pela sociedade -, outros mecanismos adicionais de proteção social, como: serviços sociais universais (saúde e educação, por exemplo), proteção ao trabalho (em apoio ao pleno emprego) e garantia do direito ao acesso a esses bens e serviços e ao seu usufruto. Esta foi a fase de ouro das políticas de proteção social, na qual a otimização da satisfação das necessidades humanas básicas tornou-se uma tendência promissora, a partir da Europa.
\end{abstract}

Portanto, segundo Pereira (2008, p. 93), em que pese as críticas que podem ser feitas à ideia de mínimos sociais, "o Sistema de Seguridade Social de Beverigde inovou, de fato, por ser nacional e unificado e conter um eixo distributivo, ao lado do contributivo, além de abolir os testes de meio no âmbito da assistência social”. Além disso, para Pereira (2000, p. 20) esse plano permitiu aos dominados uma "cultura de oposição", abrindo a possibilidade, aos desfavorecidos, de transformar suas necessidades em questões sociais e incluí-las na agenda política vigente.

Para a autora, o conceito de proteção social mínima identifica-se, nas suas origens, com um mínimo de renda. Surge, como mencionado acima, na Grã-Bretanha, em 1795, sob forma de abono salarial ou rendimento mínimo garantido, no bojo de uma sociedade ainda não completamente mercantil. Destaca, Pereira (2000, p. 105) que respaldo pela Lei do Parlamento do Condado de Speenhamland (Speenhamland Law) tal conceito marcou uma inflexão até então jamais vista na política de proteção social que vinha sendo desenvolvida na Inglaterra, desde 1536, sob a regência das velhas Leis dos Pobres (Poor Law).A prestação dos bens e serviços sociais não envolvia mais a discussão da necessidade (marca das primeiras políticas sociais inglesas que se destinavam àqueles que não poderiam participar do processo produtivo) e tampouco se pautava na base contributiva de cada indivíduo (vale dizer, no quanto cada trabalhador tinha contribuído para o serviço).

No Estado de Bem-Estar Social cabia ao Estado, conforme Marshall (1967, p. 93), garantir "um mínimo de certos bens e serviços essenciais (tais como assistência médica, moradia, educação, ou uma renda nominal mínima ou salário mínimo) a ser gasto em bens e serviços essenciais". É nesse momento em que os direitos sociais se inserem, segundo o autor, no status da cidadania, passando a provisão de serviços sociais a ser vista enquanto direito de cidadania, que devia ser assegurada a todos os indivíduos independentemente de se situarem nos grupos críticos e da sua inserção no mercado de trabalho. Nogueira (2001, p. 90). Nos 
lembra que a expressão inglesa - Welfare State foi criada da década de 40, do século XX, ainda que a menção à Welfare Policy - Política de Bem-estar, ocorra desde o início do século. Ressalta, ainda, a autora, que o Plano Beveridge, foi o primeiro documento a marcar os princípios do Welfare State. Esse documento teve repercussão em vários países, que passaram a organizar a política de segurança social com as características apontadas por Beveridge. (NOGUEIRA, 2001, p. 90).

Fundamental é a compreensão de Nogueira (2001, p. 91), ao afirmar que o crescimento econômico e demográfico explica a emergência generalizada do Welfare State. Justifica sua alegação a partir da constatação de que os padrões mínimos sob fiança governamental, de renda, nutrição, saúde, habitação e educação, assegurados como direito político, e não como caridade para todos os habitantes do país, estão relacionados aos problemas e possibilidades advindos do processo de inovação industrial..

Dessa forma, como contrapartida ao direito dos indivíduos, exsurgiu o dever do Estado de regulamentar um conjunto de garantias aos cidadãos em situação de fragilidade e infortúnio social. Pereira (2008, p. 88-89) afirma que no Welfare State, os

[...] Estado e mercado se articularam e se co-responsabilizaram pela formulação e gerenciamento de políticas favorecedora de pleno emprego e de um conjunto de benefícios e serviços que, na perspectiva dos direitos, asseguravam aceitáveis padrões de vida aos cidadãos, a saber: o seguro social obrigatório, leis de proteção ao trabalho, salários mínimos, ampliação de instituições e serviços de saúde e educação, programas de habitação subsidiados [...] No âmbito das modernas estruturas do Estado de Bem-Estar firmaram-se vigorosas forças sindicais, instituíram-se, expandiram-se e multiplicaram-se direitos de cidadania e fortaleceram-se instituições democráticas.

Como se pode observar, o Estado de Bem-Estar tem como núcleo central a seguridade social. Por essa razão, foi somente a partir deste modelo que a saúde do indivíduo entrou na agenda pública. Antes disso, no Estado Liberal, o poder público agia tão somente no âmbito da saúde coletiva, a fim de oferecer saneamento e evitar epidemia, tendo em vista que o acesso aos serviços médicos era condicionado à possibilidade dequem poderiapagar por eles (AÑÓN, 2009). Como grande parte da população não dispunha dos recursos necessários para custear as prestações sanitárias, poucos eram os que tinham acesso aos cuidados médicos, os quais, como referido acima, eram quase que restritos aos trabalhadores e suas famílias.

Com o Plano Beveridge, instituiu-se um modelo de Sistema Nacional de Saúde não contributivo, universal e financiado pelos impostos. O direito à saúde passou, então, a ser titularidade de todos os indivíduos, que podiam se valer do Sistema Nacional sem qualquer contraprestação pecuniária e independente da comprovação da necessidade social. Com esse Plano as bases da seguridade social foram modificadas. 
Añón $(2009$, p. 24) afirma que uma característica das políticas do Estado de BemEstar Social "foi a participação do Estado na promoção e proteção da saúde da população, mediante a ampliação de sistemas públicos de saúde e pelo progressivo reconhecimento e positivação do direito à saúde" ${ }^{1}$.E é em razão do movimento estatal de maior proteção à saúde, que segundo Dallari (1995, p. 25):

No início do século XX se encontra instaurada a proteção sanitária como política de governo. E são hierarquizadas três formas, hoje clássicas de prevenção: a primária, que se preocupa com a eliminação das causas de condições de aparecimento das doenças, agindo sobre o ambiente (segurança nas estradas, saneamento básico, por exemplo) ou sobre o comportamento individual (exercício e dieta, por exemplo); a secundária ou prevenção específica, que busca impedir o aparecimento de doença determinada, por meio da vacinação, dos controles de saúde, da despistagem; e a terciária, que visa limitar a prevalência de incapacidades crônicas ou de recidivas (LEAVELL; CLARK, 1976) ${ }^{2}$. O Estado do bem-estar social da segunda metade do século XX reforça a lógica econômica, especialmente em decorrência da evidente interdependência entre as condições de saúde e de trabalho, responsabilizando-se pela implementação da prevenção sanitária.

Instituem-se, então, os sistemas de previdência social, que não se limitam a cuidar dos doentes, mas organizam a prevenção sanitária. A princípio, pressupunham uma diferenciação entre assistência social, destinada às classes mais desfavorecidas e baseada no princípio de solidariedade e, portanto, financiada por fundos públicos estatais, e previdência social, mecanismo assecuratório restrito aos trabalhadores. Entretanto, exatamente porque a prevenção sanitária era um dos objetivos do desenvolvimento do Estado, logo se esclarece o conceito de seguridade social, que engloba os subsistemas de assistência, previdência e saúde públicas. Trata-se, portanto, de identificar a responsabilidade a priori do estado. Assim, quanto aos estilos de vida, verifica-se um grande investimento estatal.

À saúde foi conferida importância não somente no âmbito dos Estados, mas também no contexto internacional. Em 1946, foi criado um organismo específico para a sua proteção e promoção, a Organização Mundial da Saúde (OMS), que tem como objetivo promover a aquisição, por todos os povos, do nível de saúde mais elevado possível.

A Declaração Universal dos Direitos Humanos de 1948 também consagrou a saúde como direito humano essencial, prevendo que todo indivíduo tem direito a um padrão de vida capaz de assegurar a si e a sua família saúde e bem-estar, alimentação, vestuário, habitação, cuidados médicos e os serviços sociais indispensáveis.

O Pacto Internacional de Direitos Econômicos, Sociais e Culturais, por sua vez, realça que todos os Estados signatários reconhecem o direito de todos à fruição do mais alto nível de saúde física e mental. Eleva-se em nível internacional a questão acerca do significado da saúde, tema que, ao longo dos anos, tem suscitado inúmeras controvérsias e discussões.

\footnotetext{
${ }^{1}$ Tradução livre do trecho: “[...] ha sido la participación del Estado en la promoción y protección de la salud de la población, mediante la extensión de sistemas públicos de salud y mediante el progressivo reconocimiento y positivación de um derecho a la salud".

${ }^{2}$ Citação do próprio texto de Dallari (1995, p. 25).
} 
A presente pesquisa filiou-se à conceituação adotada pela OMS, que no preâmbulo de sua Constituição define a saúde como o "estado completo de bem-estar físico, mental e social e não meramente a ausência de doença ou enfermidade" (ORGANIZAÇÃO MUNDIAL DA SAÚDE, 1946, p. 22).Essa conceituação realça o caráter complexo e multifacetado da saúde, que não pode ser compreendida apenas como ausência de doenças, apesarde esta ser um elemento central, já que "afirma a existência de um núcleo preciso, orientando a compreensão do que, de forma clara e inquestionável, é direito subjetivo do indivíduo, ou seja, o da assistência integral, quer para tratar, quer para ainda readequar o indivíduo socialmente" (DALLARI; NUNES JÚNIOR, 2010, p. 10).

No entanto, a saúde é mais que isso, indo além da assistência médica e das ações para a promoção e manutenção de um estado saudável. Ela está relacionada com as próprias condições de vida das pessoas: meio ambiente, saneamento básico, moradia, alimentação, educação, trabalho, dentre outros.Assim, o direito à saúde "parece não ser suscetível de uma consideração simplista, apresentando-se mais como um direito complexo, isso porque agrupa uma série de direitos diversos, ou porque se desdobra em uma série de elementos de diferente alcance"3 (AÑóN, 2009, p. 41).

Nesse desiderato, o direito à saúde não pode ser compreendido na dimensão puramente individual, no sentido de que ser saudável depende tão somente do indivíduo. Ao contrário, envolve uma série de fatores individuais e coletivos, sendo a um só tempo direito individual e social. É individual porque envolve o direito de não sofrer violações por parte de terceiros e do Estado e social por exigir do governo a prestação de serviços públicos para a prevenção de doenças e para a promoção, proteção e recuperação da saúde.O direito à saúde é também um bem coletivo, exigindo a participação da sociedade e do Estado na sua promoção, conforme bem realçado na Constituição da Organização Mundial da Saúde (1946, p. 2):

\footnotetext{
A saúde de todos os povos é fundamental para se alcançar a paz e a segurança e depende da mais ampla cooperação de indivíduos e Estados.

Os resultados alcançados por qualquer Estado na promoção e proteção da saúde são valiosos para todos.

A desigualdade dos diferentes países na promoção da saúde e no controle das doenças, especialmente as transmissíveis, constitui um perigo comum.

[...]

Os governos têm responsabilidade na saúde de seus povos, a qual só pode ser integralmente cumprida mediante a adoção de medidas sanitárias e sociais adequadas.
}

Destarte, no texto normativo da OMS, ao Estado e à sociedade é conferido o dever de

\footnotetext{
${ }^{3}$ Tradução livre do trecho: "parece no ser suscetible de una consideración simplista y más bien se aparece como um derecho complejo, bien porque agrupa una serie de derechos diversos, o bien porque se despliegue en una serie de elementos de alcance diferente"
}

Barbarói, Santa Cruz do Sul, n.55, p.<57-8o>,jul./dez. 2019 
criar condições econômicas, políticas e sociais para a promoção e proteção da saúde dos indivíduos. Esse aspecto é importante, na medida em que a saúde depende não apenas de aspectos pessoais (predisposição genética, características físicas, hábitos etc.), mas também das condições de vida que a sociedade e, em especial, o poder público proporcionam ao indivíduo.

A Constituição da OMS ressalta, também, a necessidade da comunhão de esforços dos Estados para efetivação do direito à saúde. Isso se deve ao fato de que, no mundo globalizado, o intenso fluxo de pessoas e mercadorias também favorece a difusão e propagação de doenças, de forma que o combate só será eficaz se todos empreenderem esforços para o alcance de um nível de desenvolvimento semelhante na proteção da saúde e no combate às doenças, sendo que "a extensão a todos os povos dos benefícios dos conhecimentos médicos, psicológicos e afins é essencial para a mais ampla realização da saúde" (ORGANIZAÇÃO MUNDIAL DA SAÚDE, 1946).

Como se vê, a Constituição da OMS, além de conceituar a saúde, apresenta muitos aspectos a ela relacionados, sendo um marco normativo muito importante para o estudo do tema, apesar das críticas que são feitas em virtude da suposta amplitude do texto. Añón (2009, p. 49-50) observa que:

\begin{abstract}
Apesar de todos os inconvenientes, o conceito de saúde da OMS tem, frente às concepções anteriores de saúde, a vantagem de enfatizar determinados aspectos que não devem ser esquecidos, apresentando a novidade do abandono da visão puramente medicamentalizada: a proteção e promoção da saúde não é unicamente uma questão médica e tampouco limitada à assistência sanitária, uma vez que há outros esforços e políticas públicas que podem contribuir em grande medida com este objetivo. Assim, essa concepção integra a proteção da saúde em um marco geral, reconhecendo o seu duplo caráter individual e social (isto é, ainda que em última instância a saúde se refira à saúde dos indivíduos, existem fatores que são sociais - e o que talvez seja o mais importante, modificáveis - que incidem na mesma). Com isso, entende-se que a saúde implica também a existência de condições para o desenvolvimento das pessoas, sendo inseparável da paz, da eliminação da pobreza, da redução do desemprego, da preservação do meio ambiente, etc. Significa a existência de uma correlação entre saúde das pessoas e o desenvolvimento socioeconômico. Esta concepção se opõe a que se baseia na oposição saúde/enfermidade. E, além disso, neste sentido, parece frisar a possibilidade de ser guiada por estratégias não meramente curativas, mas também por estratégias amplas de promoção da saúde ${ }^{4}$.
\end{abstract}

\footnotetext{
${ }^{4}$ Tradução livre do trecho: “A pesar de todos los inconvenientes, el concepto de salud de la OMS tiene unas ventajas y enfatiza determinados aspectos que non deben ser olvidados, frente a anteriores concepciones de la salude, presenta lanovedad de abandonar lavisión puramente medicalizada: proteger y promover lasalud no es únicamente una cuestión médica ni limitada a la assistência sanitária, sino que hayotrosesfuerzos y políticas públicas que pueden contribuir engran medida a este objetivo. Así, esta concepción integra laproteción de lasaludenun marco general, recogiendosu doble cara individual y social (esdecir, aunqueen última instancia lasalud se refiere a lasalud de os indivíduos, existenfactores que sonsociales - y lo que quizásea má importante, modificables - que incidenenlamisma). Conello, se entiende que lasalud implica tambiénla existência de uns condiciones para eldesarrollo de las personas y que resulta inseparable de la paz, laeliminación de la pobreza, lareduccióndeldesempleo, laconservacióndelmedio ambiente, etc. Significa atender a la existência de una
} Barbarói, Santa Cruz do Sul, n.55, p.<57-80>,jul./dez. 2019 
O texto normativo da OMS é, portanto, referência obrigatória para a compreensão dos principais aspectos relacionados à saúde: conceito e complexidade; indissociabilidade das condições de vida das pessoas; caráter individual, social e coletivo; e a necessidade da participação da sociedade e do Estado na sua garantia.

\section{0 direito e proteção da saúde no Brasil}

A Constituição Federal de 1988 foi o primeiro texto constitucional brasileiro a tratar a saúde como direito, inserindo-a, qualidade de direito fundamental social, no seu artigo $6^{\circ}$ e no sistema da seguridade social, que, por sua vez, "compreende um conjunto integrado de ações de iniciativa dos Poderes Públicos e da sociedade, destinadas a assegurar os direitos relativos à saúde, à previdência e à assistência social” (art. 194) (BRASIL, 1988).

Ao contrário da previdência (de caráter contributivo) e da assistência social (prestada a quem está em situação de necessidade), a saúde se pauta pelo acesso universal, estando prevista como "direito de todos e dever do Estado, garantido mediante políticas sociais e econômicas que visem à redução do risco de doença e de outros agravos e ao acesso universal e igualitário às ações e serviços para sua promoção, proteção e recuperação" (CF, art. 196). Souza (2013, p. 206-207) realça que:

[...] O mencionado dispositivo é o cerne do maior número de questões enfrentadas pelo operador jurídico que se depara com lides envolvendo a temática, gerando constantes tensões institucionais diante da pródiga interpretação que geralmente a ele é atribuída pelo Judiciário e da postura mais restritiva da Administração e dos gestores da saúde, premidos pelas limitações orçamentárias.

Vale realçar desde logo que a saúde está prevista, ainda, no art. $6^{\circ}$ do texto constitucional, isto é, no rol dos direitos fundamentais sociais. No entanto, apesar de ser um direito social, o direito à saúde possui também uma dimensão subjetiva individual, sendo a um só tempo, portanto, um direito de viés programático e um direito oponível ao Estado judicialmente.

Na primeira parte do art. 196, pode-se perceber a institucionalização de um conceito amplo de saúde, incorporando-se ao contexto brasileiro a compreensão de saúde defendida desde 1948 pela Organização Mundial da Saúde, que, como visto, conceitua a saúde não apenas como a ausência de doença ou enfermidade, mas enquanto um estado de completo

correlación entre lasalud de las personas e eldesarrollo socioeconómico.Esta concepción se opone a la que se basaenlaoposiciónsalud/enfermedad, y que entiende simplesmente lasalud como ausência de enfermedad. Y además, en este sentido, parece ponerla vista enlaposibilidad de guiarse por estrategias no meramente curaticvas, sino también amplias como la promoción de la salude". 
bem-estar físico e social.

Dessa forma, a Constituição, ao preceituar que a saúde deve ser garantida mediante políticas sociais e econômicas que visem à redução do risco de doença e de outros agravos, abandonou o entendimento puramente biológico da saúde que dominava as ações estatais na área, mais voltadas, até então, para a prevenção e o tratamento das doenças contagiosas. Segundo Santos (2010, p. 150):

O primeiro enunciado do artigo - execução de políticas sociais e econômicas protetoras da saúde - vincula-se a planos e programas do Estado nacional, que devem assegurar ao indivíduo e à coletividade tudo aquilo que possa ser considerado essencial para a satisfação da saúde física, mental, psicológica, moral e social: morar bem, ter salário digno, ter mais lazer, boa educação, alimentação suficiente, segurança, previdência etc.

A saúde passou, assim, a não ser mais considerada de forma isolada, vale dizer, enquanto fenômeno relacionado somente ao homem, ao seu corpo e suas determinações genéticas. Albergou-se, também no conceito de saúde a relação do indivíduo com o ambiente social que o rodeia.

Nessa nova concepção, a saúde está interligada com o próprio modo de vida das pessoas, exigindo-se para a sua efetivação a garantia de: trabalho em condições dignas; alimentação para todos; moradia higiênica e digna; educação e informação plena; qualidade do meio ambiente; transporte seguro e acessível; repouso, lazer e segurança; direito à liberdade, à livre organização e expressão; e acesso universal e igualitário aos serviços setoriais em todos os níveis.

Em razão da correlação da saúde com fatores sociais, ambientais, econômicos e educacionais, a elaboração e execução das políticas sociais e econômicas protetoras da saúde não ficam restritas apenas ao sistema de saúde criado pela Constituição de 1988, envolvendo também outras pastas de governo, que devem trabalhar para "garantir às pessoas e à coletividade condições de bem-estar físico, mental e social”, através da promoção do acesso à alimentação, moradia, saneamento básico, meio ambiente, trabalho, renda, educação, atividade física, transporte, lazer e outros bens e serviços essenciais (Lei 8.080/90, art. $3^{\circ}$ ).

É o prescrito na segunda parte do art. 196 - a promoção do acesso universal e igualitário às ações e serviços para a promoção, proteção e recuperação da saúde - que se dirige mais especificamente ao sistema de saúde inaugurado pela ordem constitucional atual, qual seja: o Sistema Único de Saúde (SUS).

A Constituição de 1988 conceitua o SUS como uma rede regionalizada e hierarquizada de ações e serviços públicos de saúde (art. 198), traça algumas de suas diretrizes (art. 198 I a III) e atribuições (art. 200), fixa parâmetros de financiamento do sistema (art. $198 \S \S 1^{\circ}$ a $3^{\circ}$ ) e Barbarói, Santa Cruz do Sul, n.55, p.<57-80>,jul./dez. 2019 
permite a atuação da iniciativa privada de forma complementar (art. 199).

Antes da criação do SUS, as ações e serviços de saúde eram divididos entre o Ministério da Saúde e o Ministério da Previdência e Assistência Social. O primeiro responsabilizava-se pelas ações preventivas e de caráter coletivo, enquanto o segundo cuidava da assistência médica, de caráter curativo, que era assegurada somente aos trabalhadores contribuintes da previdência.

A partir da Constituição de 1988 decidiu-se pela expansão e fortalecimento do setor público, bem como pela separação da saúde da previdência social. Com o SUS, os serviços e ações de saúde passaram a ser organizados em uma rede única, de acesso universal, isto é, a fruição dos serviços da rede independe de contribuição para o sistema. Souza (2013, p. 207, grifo nosso) aponta que:

O art. 198 é a matriz constitucional do sistema único de saúde, o SUS, rede regionalizada e hierarquizada de ações e serviços públicos de saúde que constituem um sistema único, organizado de acordo com as diretrizes da descentralização, com direção única em cada esfera de governo; do atendimento integral, com prioridade para as atividades preventivas, sem prejuízo dos serviços assistenciais e da participação da comunidade, sistema este responsável pelo oferecimento de mais de $75 \%$ da assistência à saúde da população brasileira.

Em 1990 foi promulgada a Lei 8.080, conhecida como a Lei Orgânica de Saúde, para o fim de regulamentar os dispositivos constitucionais explicitados, de modo a criar condições para a promoção, proteção e recuperação da saúde, a organização e o funcionamento dos serviços correspondentes.

O Sistema Único de Saúde é constituído, nos termos da Lei 8.080/90, pelo "conjunto de ações e serviços de saúde, prestados por órgãos e instituições públicas federais, estaduais e municipais, da Administração direta e indireta e das fundações mantidas pelo Poder Público". A iniciativa privada (preferencialmente as entidades filantrópicas e sem fins lucrativos) também poderá integrar o SUS em caráter complementar, quando a disponibilidade dos serviços públicos for insuficiente para garantir o acesso e a integralidade da assistência aos cidadãos, desde que sejam mantidos os princípios do sistema e mediante contrato de direito público ou convênio.

No art. $7^{\circ}$ da Lei 8.080/90 estão previstos os seguintes princípios norteadores dos serviços e ações de promoção, proteção e recuperação da saúde: universalidade de acesso aos serviços de saúde; integralidade de assistência; preservação da autonomia das pessoas na defesa de sua integridade física e moral; igualdade da assistência à saúde, sem preconceitos ou privilégios de qualquer espécie; direito à informação; utilização da epidemiologia para o estabelecimento de prioridades, a alocação de recursos e a orientação 
programática;participação social; descentralização político-administrativa, com direção única em cada esfera de governo; integração em nível executivo das ações de saúde, meio ambiente e saneamento básico; conjugação dos recursos financeiros, tecnológicos, materiais e humanos dos entes federados; capacidade de resolução dos serviços em todos os níveis de assistência; e organização dos serviços públicos de modo a evitar duplicidade de meios para fins idênticos.

Sobre as diretrizes do SUS, é importante tecer maiores considerações sobre: a universalidade, igualdade, integralidade, unidade, descentralização e hierarquização.

O princípio constitucional da universalidade decorre do próprio caráter de direito fundamental que foi atribuído à saúde a partir do ordenamento de 1988. O direito à saúde aparece, portanto, como "um elemento intrínseco à dignidade do ser humano" (DALLARI; NUNES JÚNIOR, 2010, p. 72) e, por isso, pode ser exigido por todo o cidadão.

Desse modo, a assistência médica era de responsabilidade do Ministério de Previdência e Assistência Social, sendo prestada por meio do Instituto Nacional de Assistência Médica da Previdência Social (INAMPS) aos trabalhadores ou aos contribuintes autônomos do Instituto. As pessoas que estavam excluídas do mercado de trabalho ou que não podiam pagar as contribuições ao INAMPS estavam excluídas das prestações estatais de saúde. Em caso de doença, pagavam pelos serviços privados ou recorriam às instituições filantrópicas.

A Constituição de 1988 inseriu a saúde no capítulo da seguridade social, juntamente com a previdência e a assistência social. No entanto, a saúde pauta-se em princípios e diretrizes totalmente diferentes das observadas nas demais esferas. Enquanto a previdência tem caráter contributivo e a assistência social somente é prestada aos necessitados, a saúde tem acesso universal, devendo os serviços de prevenção e de assistência ser assegurados pelo Estado a toda a população. Dessa forma, conforme Weichert (2004, p. 158)

\section{[...] O Sistema Único de Saúde não foi formulado apenas para a população carente (como uma política de assistência social) ou para os que contribuem à seguridade social (como uma prestação previdenciária), mas sim para a garantia de saúde a todos que necessitarem e desejarem a ele (o sistema público) recorrer [...].}

Além do acesso universal, a Carta Magna previu o acesso igualitário aos serviços de saúde, o que significa que o acesso será assegurado a todos, sem distinções e privilégios. A adoção do princípio da igualdade nos serviços e ações de saúde nada mais é do que a concretização, que deve ocorrer na prestação de qualquer serviço público, da noção de igualdade refletida no caput do art. $5^{\circ}$ da $\mathrm{CF}$ e do princípio republicano insculpido no art. 19 III do texto constitucional, que veda a criação de distinções ou preferências entre brasileiros. Tal princípio pode ser sintetizado através da máxima segundo a qual a mesma situação clínica 
deve merecer a mesma atenção em saúde.

Serrano (2009, p. 76) adverte que "a conjugação dos princípios da universalidade e da igualdade acaba dando lugar à equidade”, que significa que devem ser reconhecidas as desigualdades na mortalidade e incidência de doenças entre os diferentes grupos sociais, de modo que as ações de saúde possam focar nos indivíduos mais vulneráveis (crianças, idosos, mulheres etc.), sem que isso represente afronta à igualdade preconizada no art. $5^{\circ}$ da $\mathrm{CF}$.

Outro princípio elencado no art. $7^{\circ}$ da Constituição Federal é o da integralidade, que, para Carvalho (2006), possui duas dimensões: horizontal e vertical. A primeira exige que haja a interligação de serviços de prevenção e tratamento, em âmbito individual e coletivo, devendo ser prestados em todos os níveis de complexidade. Já a dimensão vertical está relacionada ao conceito amplo de saúde, pressupondo "um olhar para as questões que envolvem o afetivo, o biológico, o espiritual, o sociocultural, entre outras" (CARVALHO, 2006, p. 16).

O princípio da unidade, por sua vez, traduz o objetivo do Sistema Único de Saúde de "articular todos os serviços existentes no país para que, atuando de forma ordenada, possa haver a otimização dos escassos recursos sociais em todos os níveis da federação, propiciando ganho de escala e evitando a sobreposição de estruturas” (SOUZA, 2013, p. 209).

É o princípio da unidade que permite ao cidadão recorrer, na falta dos serviços em sua localidade, aos serviços de saúde da municipalidade ou Estado vizinhos, bem como impede a “instrumentalização do sistema único pelo privado, proibindo que o paciente recorra ao sistema público exclusivamente para obter medicamentos, exames clínicos e tratamentos cirúrgicos prescritos por médico particular" (SOUZA, 2013, p. 210).

A descentralização, também, é um princípio organizativo do SUS, entendido como uma redistribuição de responsabilidades e recursos entre as três esferas de governo, com ênfase na municipalização, isto é, o Município é o principal responsável na garantia da saúde da população, somente podendo ser atribuídos aos Estados e à União os serviços que os Municípios não possam prestar, ou que tenham uma dimensão regional e nacional. Conforme Souza (2013, p. 213):

[...] aqui se insere a acirrada discussão sobre a modalidade de responsabilidade dos entes federados, não nos parecendo ser o melhor entendimento aquele que prega a responsabilidade solidária indiscriminadamente entre a União, os Estados e os Municípios. Isso porque, a uma, a desconsideração das divisões de competências e responsabilidades estabelecidas nos atos normativos secundários e nas leis reguladores da matéria funcionam contra a diretriz da descentralização (objetivo historicamente perseguido pelo Movimento de Reforma Sanitária e pelo constituinte como melhor caminho para a melhoria global do sistema de saúde); e, a dois, porque a condenação incidente sobre diversos entes da federação gera desperdício de recursos em um ambiente já suficientemente marcado pela escassez.

Barbarói, Santa Cruz do Sul, n.55, p.<57-8o>,jul./dez. 2019 
A regionalização refere-se à forma de organização do sistema de saúde por circunscrições territoriais (de modo a levar-se em consideração o dinamismo e a complexidade dos perfis epidemiológicos locais), enquanto o princípio da hierarquização indica a necessidade de organizar o sistema por níveis de complexidade crescentes: primário (pequena complexidade - ex: consultas e curativos), secundário (média complexidade - ex: pequenas cirurgias) e terciário (alta complexidade - ex: cirurgias mais complexas).

As diretrizes da regionalização e da hierarquização possuem dois corolários: i) o estabelecimento de um sistema de atendimento afunilado, induzindo o usuário a ter o contato inicial com o nível primário de atendimento (a grande porta de entrada do sistema) para que a partir daí possa ser encaminhado aos níveis mais complexos (que possuem demanda decrescente e custo crescente em relação ao nível primário); e ii) o oferecimento seletivo de “[...] níveis de atendimento secundário e terciário em centros regionais capazes de atender à demanda de vários pequenos municípios, priorizando a alocação de recursos no nível primário de atendimento" (SOUZA, 2013, p. 211).

Todas essas diretrizes do SUS, estabelecidas na Constituição Federal e na Lei Orgânica da Saúde, são importantes marcos para a concretização do direito à saúde, vale dizer, para, diante da sua complexidade e multiplicidade de prestações, especificar o seu âmbito de abrangência, ou pelo menos, aquilo que o direito à saúde não comporta.

Dessa forma, por um lado, faz-se necessário observar, por exemplo, que os ditames dos princípios da unidade, descentralização, hierarquia e regionalização do SUS são violados diante de determinadas decisões judiciais, como as que determinam o dispêndio de recursos públicos para o custeio de remédios, tratamentos e procedimentos prescritos exclusivamente por profissionais que não pertenciam aos quadros do sistema público; as que são proferidas sem a análise minuciosa dos atos normativos de repartição de competência e responsabilidade; e as que condenam os municípios ao fornecimento de serviços de alta complexidade ou bens de alto custo. É importante destacar que a defesa da universalidade do direito à saúde não significa que toda e qualquer pretensão de bens ou serviços de saúde deva ser concedida pelo Poder Judiciário.

Por outro lado, cabe analisar os interesses e as racionalidades políticas que têm demarcado o sistema de saúde brasileiro nas últimas duas décadas do século XXI, para que se possa compreender suas fragilidades e construir perspectivas de atuação. (SUGESTÃO DO AVALIADOR DA REVISTA)Carvalho (2013) afirma que o final do governo do Presidente da República Fernando Henrique Cardoso- FHC e eleição do presidente Luís Inácio LULA da 
Silva construiu um cenário de expectativa positiva aos grupos progressistas brasileiros, com mudanças estruturais e que, no âmbito da saúde pública, representaria a concretização das tutelas constitucionais e legais.

Para Carvalho (2013), no entanto, as expectativas foram frustradas, pois a mesma lógica mercadológica de usar todos os meios LULA e, posteriormente, aparecerão também no governo DILMA Rousseff. No âmbito da saúde, não houve diferença fundamental alguma entre a proposta dos partidos progressistas com as propostas e ações do partido conservador que o precedeu. Vianna esclarece essa observação de Carvalho (2013) com a seguinte assertiva:

\begin{abstract}
Impossível dissociar, em laboratório, as políticas do PT e do PSDB. PT e PSDB são duas colorações da mesma social democracia. São duas faces da mesma identidade política. Não há uma destinação de classe explícita: o PT é o partido dos trabalhadores, dos operários, dos camponeses e o PSDB é o partido dos capitalistas, empresários, dos economicamente privilegiados. Isso não é verdade.
\end{abstract}

Carvalho (2013) destaca, ainda, que o discurso de priorização da saúde esteve presente em todos os governos, mas, a prática da efetivação não foi alcançada em qualquer deles. $\mathrm{O}$ autor alerta que, por um lado, o presidente LULA teve em seus dois mandatos quatro ministros da Saúde, que por situações diversas, não conseguiram implementar o SUS. Por outro, os ministros da presidente DILMA, não conseguiram levar à frente uma proposta coesa e consistente de política de saúde que consolidasse o modelo pensado pelos constituintes de 1988. A concepção maniqueísta de contraposição entre financiamento e eficiência, segundo Carvalho (2013) se repetiu em ambos os governos petistas.

O autor constata em sua análise, que no âmbito da Saúde Pública o financiamento é insuficiente e que existe ineficiência, ou seja, configura-se, a pior associação e o maior obstáculo para efetivação do direito à saúde, qual seja: insuficiência e ineficiência. O processo mesmo de estruturação da burocracia do Ministério da Saúde, e, seus correlatos nos Estados e Municípios, acabam por editar diversas normas infraconstitucionais ilegais e/ou inconstitucionais, normas que satisfazem interesses circunstancias e localizados, independentemente de matiz ideológica do governo.

Carvalho (2013), ainda, demostra que o governo federal vem subfinanciando a saúde e que o Brasil gasta recursos insuficientes, mostra, ainda o baixo volume de recursos para a saúde pública das três esferas de governo. O autor observa, também, que o ano de 2003, primeiro do governo do presidenteLULA, foi aquele em que menos recursos federais foram gastos em saúde, trabalhando-se com um valor per capita. Sobre os recursos para a saúde, 
Carvalho (2013) relembra o processo em 2007, para a aprovação da CPMF e o processo para aprovação dos $10 \%$ da Receita Corrente Bruta para a saúde, relata o autor:

Em 2007 - primeiro ano do segundo mandato de Lula, deveria ser votada a prorrogação da CPMF. Passou pela Câmara e foi ao Senado. O Senado endureceu, principalmente por ter maioria oposicionista. Fez uma exigência a Lula de que só aprovaria se todos os recursos da CPMF fossem destinados à saúde (cerca de R $\$ 40$ bi à época). Lula não cedeu por achar que conseguiria a maioria necessária dos votos. Depois de praticamente perdida as chances de aprovação, Lula manda ao Senado um ofício dizendo que os recursos todos seriam aplicados em saúde. A oposição tripudiou depois de tardiamente o presidente ter se colocado de joelhos e votou contra a prorrogação da CPMF. Perdemos todos, pois o projeto de Roberto Gouveia já havia sido votado na Câmara e contando com a permanência da CPMF. Diante disso este projeto enviado ao Senado morreu.O Senado, também em 2007, apreciou um projeto do senador Tião Viana, médico do PT, destinando $10 \%$ da Receita Corrente Bruta para a saúde. Foi aprovado por unanimidade pelos senadores de oposição e situação. Foi encaminhado à votação da Câmara. O governo, mais que depressa, colocou um relator médico petista, alinhado com o palácio, que apresentou um substitutivo ao do senado. Voltou-se à redação anterior da Câmara e foram retirados os $10 \%$ da Receita Corrente Bruta e criando-se a CPMF (agora CSS) com alíquota menor e destinada só à saúde. No final a Câmara aprovou o substitutivo e derrubou a CPMF (agora CSS). Como houve modificação substantiva na Câmara, o projeto voltou ao Senado. Grande expectativa. No Senado o projeto dele com $10 \%$ da RCB foi aprovado por unanimidade e o da Câmara, exatamente o contrário, e mantendo tudo como antes constante da EC-29. Por ordem expressa da presidente Dilma, o Senado, agora favorável ao governo, votou pelo projeto da Câmara. São momentos que demonstram a distância entre o discurso de privilegiar a saúde e o de asfixiá-la pelo subfinanciamento.

Com essa considerações e a partir das constatações apresentadas no artigo "Brazil's unified health system: the first 30 years and prospects for the future", publicado em 11 de julho de 2019 no periódico The Lancet, pode-se destacar que as principais conquistas obtidas nos últimos 30 anos com o Sistema Único de Saúde (SUS) estão em processo de deterioração, em especial, com vigência da na Emenda Constitucional $n^{\circ} .95$ e no aprofundamento das políticas do governo adotadas a partir do governo DILMA (CASTRO et al, 2019).

Ressalta o estudo referenciado que em 2018, o Sistema Único de Saúde (SUS) brasileiro completou 30 anos, destaca Castro et al (2019) que essas três décadas foram marcadas por reduções na desigualdade do acesso aos serviços de saúde, declínios na mortalidade e hospitalizações evitáveis e acesso quase universal aos cuidados de saúde. No entanto, essas conquistas não suplantam o fato, segundo a pesquisa, de o SUS esteja subfinanciado e não tenha sido totalmente implementado.

Para finalizar, apesar de todas essas adversidades, deve-se destacar que a defesa da saúde como um direito fundamental, aliada à criatividade e à capacidade de superar infortúnios, fez do SUS um exemplo de inovação de sistemas de saúde para a América Latina e referência para o mundo (CASTRO et al, 2019). Aqui, cabe avultar Delduque et al (2013) na compreensão que o SUS é uma política de Estado e não de governo, em suas palavras: 
É forçoso reconhecer, igualmente que as políticas públicas ditas de Estado estão conformadas na Constituição e em leis federais, posto que tais normas de direito têm como característica sua perenidade, sendo bastante complexa sua revogação ou alteração. Tal característica do instrumento normativo garante uma vida longa à política pública. O maior exemplo deste tipo de política é o Sistema Único de Saúde, a mais importante política para a garantia do direito fundamental social à saúde. Estando descrita em sede constitucional e complementada por leis federais, tem sua perenidade garantida apesar dos governos e do transcurso do tempo.

Neste sentido, deve buscar, com inspiração em Bobbio (2004), que o direito à saúde seja um compromisso com a justiça social, abrangendo a questão da distribuição de renda e enfrentamento às desigualdades. O direito à saúde deve incluir como proteção fundamental, os grupos vulneráveis, ou seja, as necessidades fundamentais não podem estar condicionadas à caridade, mas estruturadas em políticas públicas que consolidem e garantam a concretização dos direitos insculpidos na Constituição Federal de 1988.

\section{CONSIDERAÇÕES FINAIS}

Destacou-se que o ápice do princípio da proteção social somente foi alcançado após a Segunda Guerra Mundial, quando o capitalismo, diante do quadro de instabilidade política, social e econômica mundial, precisou se reinventar, fundamentalmente pela necessidade de sua própria manutenção. Acabou por acolher demandas por maior igualdade, reconhecimento dos direitos sociais e segurança econômica, elementos decisivos no processo de constituição do Estado de Bem-Estar Social.

Constatou-se que no Estado de Bem-Estar Social cabe ao Poder Público, na concepção de Marshall (1967), a garantia de mínimos sociais e por conseguinte de direitos sociais que passam a estar inseridos no status da cidadania. Por sua vez, verificou-se que a seguridade social passou a ser o núcleodesse modelo de estado, por essa razão, foi somente a partir desse arquétipo organizacional que a saúde do indivíduo entrou na agenda pública como direito fundamental social.

Destacou-se que, no final da primeira metade do século $\mathrm{XX}$, à saúde foi conferida importância não somente no âmbito dos Estados, mas também no contexto internacional, essa ideia pode ser constatada com a criação de um organismo específico para a sua proteção e promoçãoa Organização Mundial da Saúde - OMS (1946), organismo que se estabeleceu com objetivo de promover a aquisição, por todos os povos, do nível de saúde mais elevado possível.

Evidenciou-se que no Brasil, a Constituição Federal de 1988 foi um marco decisivo na afirmação do direito à saúde, inserto em capítulo dirigido à seguridade social. Demonstrou-se Barbarói, Santa Cruz do Sul, n.55, p.<57-80>,jul./dez. 2019 
que o direito à saúde está em condição diversa da previdência e da assistência sociais, na medida que se fundada nos princípios da igualdade e universalidade. Destacou-se, por conseguinte, a criação do Sistema Único de Saúde - SUS, que representou uma etapa peremptória no processo de conquistas e efetivação do direito à saúde.

Por fim, ressaltou-se que o conteúdo do direito à saúde não se resume a uma perspectiva biológica, condensada meramente na ideia de ausência de doença, na verdade estávinculado aos aspectospróprios do modo de vida das pessoas, exigindo-se para a sua efetivação a garantia de outros direitos fundamentais, quais sejam: trabalho em condições dignas; alimentação para todos; moradia higiênica e digna; educação e informação plena; qualidade do meio ambiente; transporte seguro e acessível; repouso, lazer e segurança; direito à liberdade, à livre organização e expressão; e acesso universal e igualitário aos serviços setoriais em todos os níveis.

\title{
POVERTY, SOCIAL PROTECTION AND CITIZENSHIP: AN ANALYSIS OF THE RIGHT TO HEALTH IN BRAZIL FROM THE FEDERAL CONSTITUTION OF 1988
}

\begin{abstract}
The purpose of this article was to analyze the process of constitution of the idea of the right to health as a social right in Brazil, as part of the list of fundamental rights inscribed in the Federal Constitution of 1988. For this purpose, a concise historical irruption was made in the process of conception of social protection in western Europe. The objective was also to analyze social protection as an essential element of citizenship. We sought to understand social security as the core of the welfare state and to discuss the context of insertion of the right to health issue in the public agenda. This research used the deductive research method, with the appropriation of the concepts of social protection and social rights, reflecting on the determinations of the contents present in the constitutional conception of the right to health.

Keywords: Social Protection. Right to Health. Federal Constitution.
\end{abstract}

\section{Referências}

AÑÓN, Carlos Lena. Salud, justicia, derechos: el derecho a la salude como derecho social.Madri: Dyknson, 2009.

BOBBIO, Norberto. A era dos direitos. Trad. Carlos Nelson Coutinho. Rio de Janeiro: Elsevier, 2004.

BRASIL. Constituição da República Federativa do Brasil de 1988. Disponível em: <http://www.planalto.gov.br/ccivil_03/constituicao/constituicao.htm>. Acesso em 5 fev. 2015.

BRASIL. Lei 8.080, de 19 de setembro de 1990. Disponível em: <http://www.planalto.gov.br/ccivil_03/leis/18080.htm>. Acesso em 5 fev. 2015.

CASTRO et al. Brazil's unified health system: the first 30 years and prospects for the future. Barbarói, Santa Cruz do Sul, n.55, p.<57-80>,jul./dez. 2019 
Published online. Jult 11, 2019. Disponível em <https://www.abrasco.org.br/site/wpcontent/uploads/2019/07/PIIS0140673619312437.pdf〉. Acesso em 16 nov 2019.

CARVALHO, Gilson. Os governos trincam e truncam o conceito da integralidade. Radis, Rio de Janeiro, n. 49, ago. 2006. Disponível em:<http://www6.ensp.fiocruz.br/radis/revistaradis/49/reportagens/“"os-governos-trincam-e-truncam-o-conceito-da-integralidade>. Acesso em: 12 maio 2015.

CARVALHO, Gilson. A saúde pública no Brasil. Estudos Avançados 27 (78), 2013. Disponível em:<http://www.scielo.br/pdf/ea/v27n78/02.pdf〉. Acesso em: 10 out 2019

DALLARI, Sueli Gandolf. Os estados brasileiros e o direito à saúde. São Paulo: Hucitec, 1995.

DALLARI, Sueli Gandolf; NUNES JÚNIOR, Vidal Serrano. Direito sanitário. São Paulo: Verbatim, 2010.

DELDUQUE, Maria Célia. MARQUES, Silvia Badim. CIARLINI, Álvaro. Judicialização das políticas de saúde no Brasil. In.: Direito Sanitário em Perspectiva. Org. ALVES, Sandra Mara Campos. DELDUQUE, Maria Célia. DINO NETO, Nicolao. Brasília: ESMPU: FIOCRUZ, 2013.

GIOVANNI, Geraldo di. Sistema de proteção social: uma introdução conceitual. In: OLIVEIRA, Marco Antônio. (Org.). Reforma do Estado e políticas de emprego no Brasil. Campinas, São Paulo: UNICAMP, IE, 1998.

MARCONI, Marina de Andrade. LAKATOS, Eva Maria. Metodologia científica. 5. Ed. Rio de Janeiro: Atlas, 2007.

LIMA, Javert de Sousa. Da mensagem de Bismarck ao Plano Beveridge. Revista da Faculdade de Direito da UFMG. Vol. 09, 1957. Disponível em:

$<$ https://www.direito.ufmg.br/revista/index.php/revista/article/view/604> Acesso em 10 out 2019.

MARSHALL, Thomas Humphrey. Cidadania, classe social e status. Rio de Janeiro: Zahar, 1967.

NOGUEIRA, Vera Maria Ribeiro. Estado de bem-estar social - origens e desenvolvimento. Katálysis, n. 5, jul.dez., 2001. Disponível em <https://periodicos.ufsc.br/index.php/katalysis/article/view/5738>. Acesso em 10 out 2019.

\section{ORGANIZAÇÃO MUNDIAL DA SAÚDE. Constituição da Organização Mundial da}

Saúde. São Paulo: Unesp, 1946. Disponível em: < http://www.direitoshumanos.usp.br/index.php/OMS-Organização-Mundial-daSaúde/constituicao-da-organizacao-mundial-da-saude-omswho.html>. Acesso em: 31 jan. 2015.

PEREIRA, Potyara Amazoneida. Política social: temas \&questões. São Paulo: Cortez, 2008. 
PEREIRA, Potyara Amazoneida. Necessidades humanas: subsídios à crítica dos mínimos sociais. São Paulo: Cortez, 2000.

PEREIRA, Camila Potyara. A pobreza, suas causas e interpretações: destaque ao caso brasileiro. SER Social, n. 18, p. 229-252, 14 ago. 2009.Disponível em:

<https://periodicos.unb.br/index.php/SER_Social/article/view/12996>. Acesso em: 31 jan. 2019.

POLANYI, Karl. A grande transformação: as origens de nossa época. 3. ed. Rio de Janeiro: Campus, 1980.

SANTOS, Lenir. Direito à saúde e Sistema Único de Saúde: conceito e atribuições. O que são ações e serviços de saúde. In: SANTOS, L (Org.). Direito da Saúde no Brasil. Campinas: Saberes, 2010. p. 145-179.

SERRANO, Mônica de Almeida Magalhães. O Sistema Único de Saúde e suas diretrizes constitucionais. São Paulo: Verbatim, 2009.

SOUZA, Jorge Munhós de. Diálogo institucional e direito à saúde. Salvador: JusPODIVM, 2013.

VIANNA, Luis Werneck. Revista POLI: saúde, educação e trabalho - jornalismo público para o fortalecimento da Educação Profissional em Saúde. Ano V - No 25 - set./dez. 2012.

Disponível em: 〈http://www.epsjv.fiocruz.br/sites/default/files/revista_poli___25.pdf $>$.

Acesso em: 16 out 2019.

WEICHERT, Marlon Alberto. Saúde e federação na Constituição brasileira. Rio de Janeiro: Lumen Juris, 2004.

Data de recebimento: $24 / 06 / 2016$

Data de aceite: 13/11/2019

\section{Sobre as autoras:}

Edith Maria Barbosa Ramos é Pós-Doutora em Direito Sanitário pela Fundação Oswaldo Cruz - FIOCRUZ/Brasília/DF. Doutora em Políticas Públicas pela Universidade Federal do Maranhão. Mestre em Direito pela Universidade Federal de Minas Gerais. Graduada em Direito pela Universidade Federal do Maranhão. Professora do Departamento de Direito e do Mestrado em Direito e Instituições do Sistema de Justiça da Universidade Federal do Maranhão. Coordenadora do Núcleo de Estudos em Direito Sanitário (NEDISA/UFMA). Professora e Pesquisadora da Universidade CEUMA. Professora do IMEC. Membro Convidado da Rede Ibero-Americana de Direito Sanitário. Presidente da Comissão de Bioética e Biodireito - Seccional da OAB/MA. Endereço Eletrônico: edithramosadv@yahoo.com.br

Isadora Moraes Diniz é Mestre em Direito e Instituições do Sistema de Justiça (UFMA). Pósgraduanda em Direito Processual Civil (Damásio Educacional). Graduada em Direito (UFMA). Professora do IMEC. Integrante do Núcleo de Estudos em Direito Sanitário (NEDISA/UFMA). 